\title{
Preparation and Characterization of a Sol-Gel AHEC Pore-Sealing Film Prepared on Micro Arc Oxidized AZ31 Magnesium Alloy
}

\author{
Longlong Zhang ${ }^{1}$, Yuanzhi Wu ${ }^{1}$, Tian Zeng ${ }^{1}$, Yu Wei ${ }^{1}$, Guorui Zhang ${ }^{1}$, Jun Liang ${ }^{2}$ and Baocheng Cao ${ }^{1, *}$ \\ 1 School of Stomatology, Lanzhou University, Lanzhou 730000, China; llzhang2018@lzu.edu.cn (L.Z.); \\ wuyzh14@lzu.edu.cn (Y.W.); zengt19@lzu.edu.cn (T.Z.); weiyu19@lzu.edu.cn (Y.W.); \\ zhanggr20@lzu.edu.cn (G.Z.) \\ 2 State Key Laboratory of Solid Lubrication, Lanzhou Institute of Chemical Physics, Chinese Academy of \\ Sciences, Lanzhou 730000, China; jliang@licp.cas.cn \\ * Correspondence: caobch@lzu.edu.cn; Tel.: +86-931-891-5051
}

check for updates

Citation: Zhang, L.; Wu, Y.; Zeng, T.; Wei, Y.; Zhang, G.; Liang, J.; Cao, B.

Preparation and Characterization of a Sol-Gel AHEC Pore-Sealing Film Prepared on Micro Arc Oxidized AZ31 Magnesium Alloy. Metals 2021, 11,784. https://doi.org/10.3390/ met11050784

Academic Editor: Leszek

Adam Dobrzanski

Received: 23 March 2021

Accepted: 8 May 2021

Published: 12 May 2021

Publisher's Note: MDPI stays neutral with regard to jurisdictional claims in published maps and institutional affiliations.

Copyright: (c) 2021 by the authors. Licensee MDPI, Basel, Switzerland. This article is an open access article distributed under the terms and conditions of the Creative Commons Attribution (CC BY) license (https:/ / creativecommons.org/licenses/by/ $4.0 /)$.

\begin{abstract}
The purpose of this study was to improve the cellular compatibility and corrosion resistance of AZ31 magnesium alloy and to prepare a biodegradable medical material. An aminated hydroxyethyl cellulose (AHEC) coating was successfully prepared on the surface of a micro-arc oxide +AZ31 magnesium alloy by sol-gel spinning. The pores of the micro-arc oxide coating were sealed. A polarization potential test analysis showed that compared to the single micro-arc oxidation coating, the coating after sealing with AHEC significantly improved the corrosion resistance of the AZ31 magnesium alloy and reduced its degradation rate in simulated body fluid (SBF). The CCK-8 method and cell morphology experiments showed that the AHEC + MAO coating prepared on the AZ31 magnesium alloy had good cytocompatibility and bioactivity.
\end{abstract}

Keywords: AZ31 magnesium alloy; corrosion; pore-sealing; aminated hydroxyethyl cellulose; biological materials; cytotoxicity

\section{Introduction}

Metal biomaterials have been widely used in cardiovascular, orthopedic, and oral treatment due to their excellent mechanical strengths and good biocompatibility [1-4]. Traditional metal implants must be removed by secondary surgery [5-7]. Implants made of magnesium alloys can be degraded in the human body after use, eliminating the need for secondary removal of the implants $[6,8,9]$. In addition, as biodegradable materials, magnesium alloys have many advantages: (i) they provide essential elements in human body, (ii) high content of magnesium in bone tissue, (iii) they exhibit good biocompatibility and bioactivity, (iv) they possess similar mechanical properties to those of bone tissue, and (v) they have similar modulus of elasticity to that of bone [8-10]. Compared with traditional metal implants, such as stainless steel (190 GPa), cobalt-chromium (230 GPa) and titanium (110 GPa), the elastic modulus of magnesium alloy (41 45 GPa) is more similar to that of bone tissue (30 GPa) [11]. The similar elastic modulus can avoid the stress shielding effect of magnesium alloy after implantation. The stress shielding effect may hinder fracture healing. Therefore, magnesium alloys are widely used in absorbable stents [12] and fracture fixation devices [13] in recent years.

However, magnesium alloys are chemically active and corrode easily in acidic and alkaline liquids [14]. The entire process of bone regeneration takes at least 4-16 weeks [15], During this period, the magnesium alloy will lose mechanical stability due to corrosion [14]. Furthermore, a large amount of hydrogen is produced during magnesium degradation, resulting in loosening between the metal and the bone tissue [16-18]. All these factors limit the application of magnesium alloys in the medical field. 
To overcome these shortcomings, it is necessary to improve the corrosion resistance of the AZ31 magnesium alloy. Micro-arc oxidation (MAO), also known as micro-plasma oxidation or anode spark deposition, is a widely used surface modification method for magnesium alloys. The oxidation layer is directly grown in situ on the surfaces of magnesium alloys to improve their corrosion resistances [19-21]. However, the oxide layer formed after MAO has many micro-pores and cracks on its surface. The pores and cracks can provide a channel for corrosion, which is not conducive to the protection of magnesium alloys $[22,23]$. Pore-sealing is the main method to improve this defect $[22,24]$. As a common pore-sealing method, the sol-gel method is widely used because of its simple operation and good pore-sealing effect [25-27].

Cellulose is a natural polymer, and it is the most abundant renewable polymer in nature [28]. Due to its non-toxic and biodegradable natural properties, cellulose can be widely used in the development of new materials [29,30]. Hydroxyethyl cellulose is a non-ionic water-soluble cellulose ether, which is one of the most widely used cellulose derivatives [31].

Cellulose derivatives, known as corrosion inhibitors, include carboxymethyl cellulose, hydroxypropyl cellulose, hydroxypropyl methyl cellulose and aminated hydroxyethyl cellulose (AHEC) [32]. Studies have shown that AHEC has a higher corrosion inhibition effect than other cellulose derivatives [33].

However, there has been little research on sol-gel AHEC pore-sealing of MAO coating. In this study, the feasibility of aminated hydroxyethyl cellulose pore-sealing was studied, and its cellular compatibility and corrosion resistance were evaluated to prepare a biodegradable medical material.

\section{Materials and Methods}

\subsection{Materials}

An AZ31 magnesium alloy plate was cut into $20 \mathrm{~mm} \times 20 \mathrm{~mm} \times 1 \mathrm{~mm}$ specimens using a laser cutting method. The samples were ground and polished sequentially with \#800, \#1000, \#1500, and \#2000 sandpaper. First, ultrasonic cleaning with acetone was performed for $10 \mathrm{~min}$ and then with anhydrous ethanol for $10 \mathrm{~min}$ to remove oil stains, after which the specimens were cleaned with deionized water and hot blow-drying. The samples were divided into three groups: a blank group (AZ31 magnesium alloy), control group (MAO + AZ31 magnesium alloy), and experimental group (AHEC + MAO + AZ31 magnesium alloy).

\subsection{Micro-Arc Oxidation (MAO) Coating Preparation}

First, $10 \mathrm{~g}$ of $\mathrm{KF}, 3 \mathrm{~g}$ of $\left(\mathrm{NaPO}_{3}\right)_{6}$ and $2 \mathrm{~g}$ of $\mathrm{NaOH}$ were successively added into $1 \mathrm{~L}$ of deionized water and stirred by a magnetic mixer until all the materials were dissolved. The MAO coating was prepared using this solution. In the process of micro-arc oxidation, the constant pulse frequency is $1000 \mathrm{~Hz}$. MAO treatment was carried out at constant voltage (unipolar pulse) for $7 \mathrm{~min}$. The pool temperature, final voltage and duty cycle were $20{ }^{\circ} \mathrm{C} \pm 2{ }^{\circ} \mathrm{C}, 340 \mathrm{~V}$ and $40 \%$, respectively.

\subsection{Aminated Hydroxyethyl Cellulose (AHEC) Coating Preparation}

First, $0.5 \mathrm{~g}$ of hydroxyethyl cellulose (HEC), $0.7 \mathrm{~g}$ of (2-chloroethyl) diethylamine hydrochloride (DEH) and $0.3 \mathrm{~g}$ of $\mathrm{NaOH}$ were successively added into $30 \mathrm{~mL}$ of deionized water. The reaction was completed after stirring for $30 \mathrm{~min}$ at $50{ }^{\circ} \mathrm{C}$. The AHEC was prepared by precipitation in acetone, after which it was dried with anhydrous ethanol [34].

Next, $0.45 \mathrm{~g}$ of AHEC was dissolved in $15 \mathrm{~mL}$ of deionized water and stirred at $50{ }^{\circ} \mathrm{C}$ to prepare sol-gel AHEC. Sol-gel AHEC was applied on the surface of the micro-arc-oxidized AZ31 magnesium alloy and rotated with a spin coater. The samples were rotated on the spin coater (VTC-50A, Beijing Siyouyen Electronics Technology Co., Ltd., Beijing, China) with two states (S). S1 was $2000 \mathrm{rpm}$ for $6 \mathrm{~s}$, then S2 was $6000 \mathrm{rpm}$ for $12 \mathrm{~s}$. The operation 
was repeated on the surface eight times. After the film was completely dry, the coating was rotated on the opposite surface in the same way.

\subsection{Surface Characterization}

The surface and cross-sectional morphologies were tested by scanning electron microscopy (NSM-5600LV, JEOL, Tokyo, Japan). The thickness of different coatings was measured by digital eddy current thickness gauge, 10 sites were selected on each surface, and the average thickness was taken. To improve the electrical conductivity of the samples, the surfaces of the materials were sprayed with gold. Fourier-transform infrared spectroscopy (FT-IR, NEXUS 670, Nicolet, USA), X-ray diffraction (XRD, D/MAX-2400, Rigaku Co., Ltd., Tokyo, Japan) and energy-dispersive $X$-ray spectroscopy (EDS, Hitachi S-4800, Hitachi, Ltd., Tokyo, Japan) were used to analyze the elemental compositions of the coatings.

\subsection{Corrosion Resistance Evaluation}

\subsubsection{Tafel Test}

The electrochemical system was used to evaluate the corrosion characteristics of the AZ31 magnesium alloy, MAO coating and MAO coating after AHEC sealing. The simulated body fluid (SBF) used in the electrochemical tests was prepared according to the method introduced by Kokubo and Takadama [35]. A three electrode battery and electrochemical workstation (Autolab PGSTAT302N) were used for electrochemical tests. The working electrode, reference electrode and counter electrode were the samples, an Ag/ AgCl electrode (saturated with $\mathrm{KCl}$ ) and a platinum plate, respectively. The sweep speed of the potentiodynamic curve was $1 \mathrm{mV} / \mathrm{s}$, and the measured voltages ranged from $-2.0 \mathrm{~V}$ to $-1.0 \mathrm{~V}$. Before this test, the samples were soaked in SBF solution for $30 \mathrm{~min}$ to obtain a stable open circuit potential (OCP). The exposed area was $0.5 \mathrm{~cm}^{2}$. The Tafel approximation was used to calculate the current density. After the test, the measured potentiodynamic curve was fitted according to the following formula to obtain the self-etching current density. All the measurements were repeated three times to ensure repeatability.

In this formula, E: polarization potential.

$$
I=I_{c o r r} \exp \left[\frac{-(E-E c o r r)}{\beta_{c}}\right]
$$

$I$ : polarization current density $E_{\text {corr }}$ : Self-corrosion potential $\beta_{c}$ : Cathode polarization curve $E-E_{\text {corr }}<$ The slope at $20 \mathrm{mV}, E_{\text {corr }}$ is the potential corresponding to the lowest current density in the potentiodynamic curve.

\subsubsection{Hydrogen Evolution Experiment}

To evaluate the corrosion resistances of the samples, hydrogen evolution tests were carried out with a special device described by Bakhshag-RAD et al. [36]. The amount of hydrogen evolution per day for each group was recorded. The SBF solution was replaced every $24 \mathrm{~h}$, and the experiments were performed for 7 days. To ensure the repeatability of the experimental results, the experiment was repeated three times, and the mean value \pm (standard deviation) of each group was measured as the final result.

\subsubsection{Long-Term Immersion Experiment}

A long-term immersion experiment was used to observe the surface changes with the immersion time from a macro-perspective. Before soaking, all the sample surfaces except the test surfaces were sealed with protective paint to prevent edge effects. Three groups of samples were placed in a beaker with $1 \mathrm{~L}$ of SBF, and the beaker was then placed in a constant-temperature device $\left(37.5^{\circ} \mathrm{C}\right)$. The solution was changed every 2 days, and the corrosion point was recorded with a digital camera. 


\subsection{Biocompatibility Evaluation \\ Cytotoxicity Test}

The materials of each group were immersed in the culture medium at a ratio of $1 \mathrm{~cm}^{2} / \mathrm{L}$ and placed in an incubator at $37{ }^{\circ} \mathrm{C}$ under an atmosphere of $5 \% \mathrm{CO}_{2}$. After $24 \mathrm{~h}$, the extracts were removed, filtered, and stored as the cell culture medium of each group in an environment at $4{ }^{\circ} \mathrm{C}$. At the same time, MC3T3-E1 cells were inoculated on a 12-well culture plate with a density of $5 \times 10^{4} \mathrm{cells} / \mathrm{mL}$. MC3T3-E1 is a mouse precranialparietal bone cell line, which is a good model for studying osteoblast differentiation in vitro. Under suitable culture conditions, they can differentiate into pre-osteoblasts, mature osteoblasts and osteocytes. Our research is about the biodegradable metal implants of AZ31 magnesium alloy. Therefore, MC3T3-E1 osteoblasts were selected. The purpose of this study was to explore the effects of magnesium alloy and different coatings on the viability of MC3T3-E1 cells in vitro. After the cells fully adhered to the wall for $24 \mathrm{~h}$, the extracts were replaced as the culture medium for each group, and the culture medium for the negative group, remained unchanged. During the culture, the growth status of each group was observed and recorded under an inverted microscope.

After 1, 3, and 5 days of culturing in each group, CCK-8 reagent (CCK-8: culture medium was 1:10, prepared in advance) was added to a 12-well plate with $500 \mu \mathrm{L}$ for each well to ensure the coverage of all cells. After 2-4 h of cell culturing in the cell culture chamber, 96-well plates with $100 \mu \mathrm{L}$ per well were inhaled to prevent the formation of bubbles that could affect the accuracy of the final measurement results. The absorbability (optical density, OD) of each group of samples was measured at $450 \mathrm{~nm}$ using an automatic microplate reader (Elx 800, Bio-Tek, Winooski, VT, USA). Each group was measured three times to ensure the accuracy of the experiment, and an unpaired single-tail T-test was performed on the data, with $p<0.05$ considered to be statistically significant.

\section{Results and Discussion}

\subsection{Sample Characterization}

Figure 1 shows the surface morphologies of the AZ31 magnesium alloy substrate (Figure 1a,d), MAO + AZ31 magnesium alloy (Figure 1b,e), and AHEC + MAO + AZ31 magnesium alloy sealed with aminated hydroxyethyl cellulose (Figure $1 \mathrm{c}, \mathrm{f})$. The upper raw (Figure 1a-c) were SEM images of three groups at $1000 \times$, the lower raw(Figure $1 \mathrm{~d}-\mathrm{f}$ ) were SEM images of three groups at $2000 \times$. As shown in Figure 1a,d, there were many scratches on the surface of AZ31 magnesium alloy substrate, which formed during the polishing of the substrate. As shown in Figure 1b,e, after the MAO treatment, the scratches disappeared on the sample surface, but there were more randomly distributed pores and cracks of different sizes. This was due to the formation of pores in the molten oxides and the emission of bubbles from the micro-arc discharge channels, while the microcracks were caused by the thermal stress due to the rapid solidification of molten oxides in the relatively cooled electrolyte [37,38]. As shown in Figure 1c,f, the sol-gel AHEC layer covered most of the pores and microcracks in the MAO coating well, and the microcracks were barely visible on the surface layer. At the same time, the gelation conditions may have also played an important role in reducing microcracks on the MAO coating [39,40].

Figure 2a-c shows the cross-sectional morphology of the MAO + AZ31 magnesium alloy under different magnifications $(1000 \times, 2000 \times, 5000 \times)$. Since the micro-arc oxide coating was porous and cracked, the interface between it and the substrate was irregular and wavy. Figure $2 \mathrm{~d}-\mathrm{f}$ shows the cross-sectional morphologies of the AHEC + MAO + AZ31 magnesium alloy under different magnifications $(1000 \times, 2000 \times, 5000 \times)$. The composite coating was composed of a MAO layer and a sol-gel layer [39]. Table 1 shows the thickness of different coating. With AHEC spun on MAO layer, the thickness of the composite coating was significantly greater than that of the micro-arc oxidation coating. 


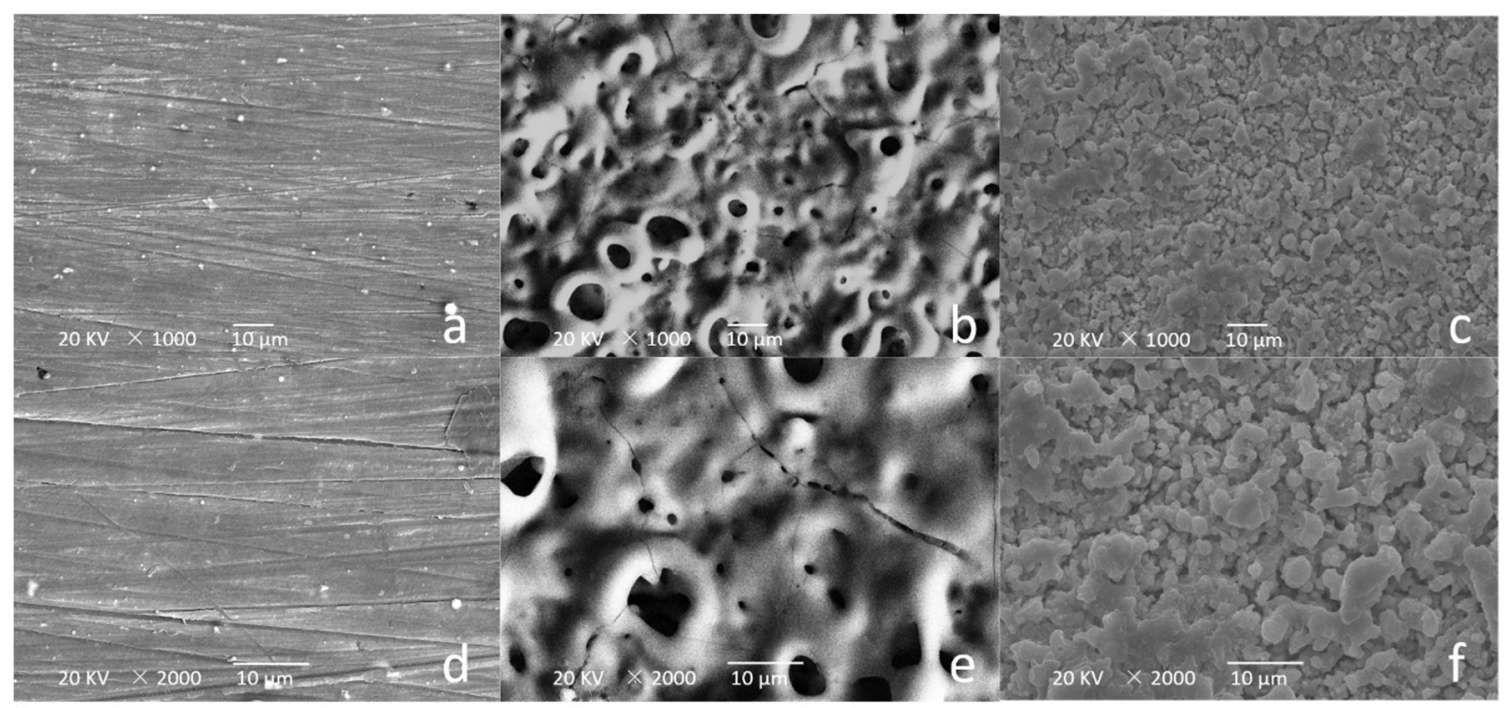

Figure 1. Scanning electron microscopy (SEM) images of (a,d) AZ31, (b,e) micro-arc oxide (MAO) + AZ31, and (c,f) aminated hydroxyethyl cellulose (AHEC) + MAO + AZ31.

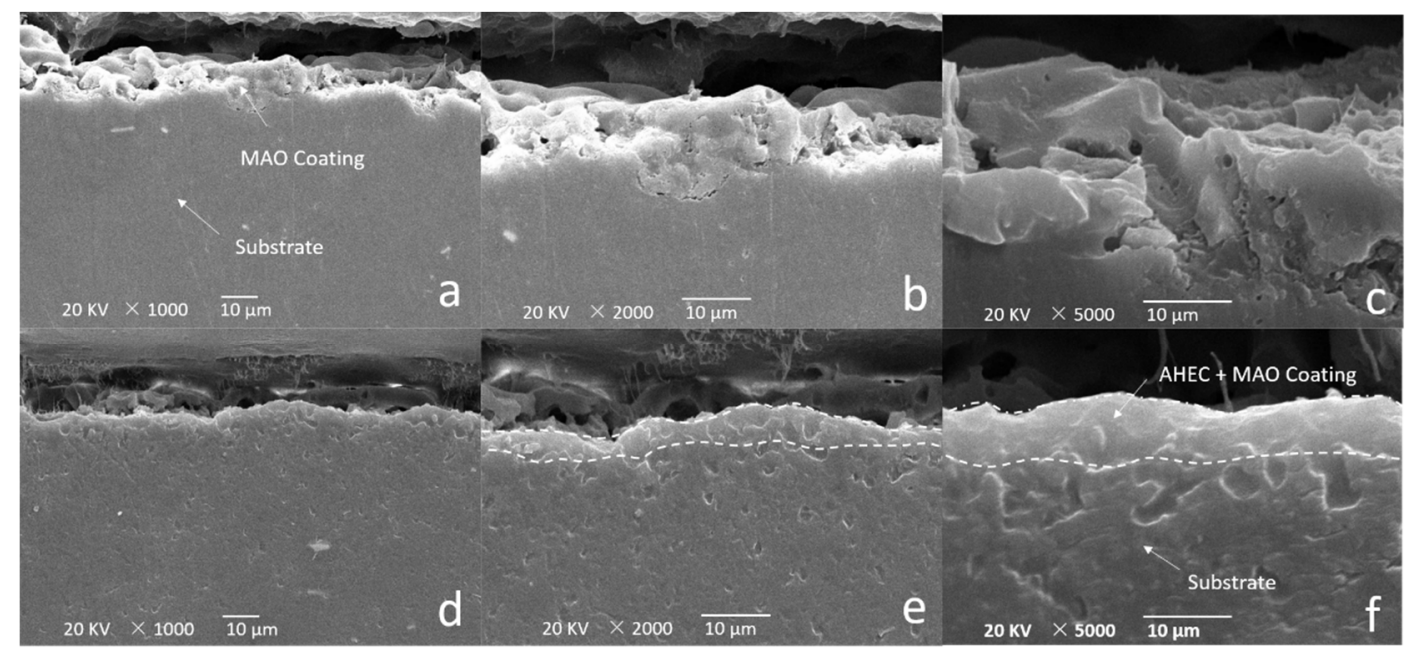

Figure 2. Cross-sectional morphologies of $(\mathbf{a}-\mathbf{c}), \mathrm{MAO}+\mathrm{AZ31}$ and $(\mathbf{d}-\mathbf{f}) \mathrm{AHEC}+\mathrm{MAO}+\mathrm{AZ31}$.

Table 1. Coating thickness of AZ31 substrate (mean \pm standard deviation).

\begin{tabular}{ccc}
\hline Samples & MAO & AHEC + MAO \\
\hline Thickness $(\mu \mathrm{m})$ & $23.52 \pm 1.42$ & $27.83 \pm 0.93$ \\
\hline
\end{tabular}

Figure 3 shows the X-ray diffraction (XRD) patterns of the AZ31, MAO + AZ31, and $\mathrm{AHEC}+\mathrm{MAO}+\mathrm{AZ31}$.In addition to the three characteristic peaks of the magnesium alloy, it can be seen that the micro-arc oxidation coating is mainly composed of $\mathrm{MgO}$ [41], and the characteristic peak of $\mathrm{MgF}_{2}$ also appears [42]. Compared with the AZ31 group, the AHEC group showed no characteristic peaks. This was attributed to the thinness of the film. 


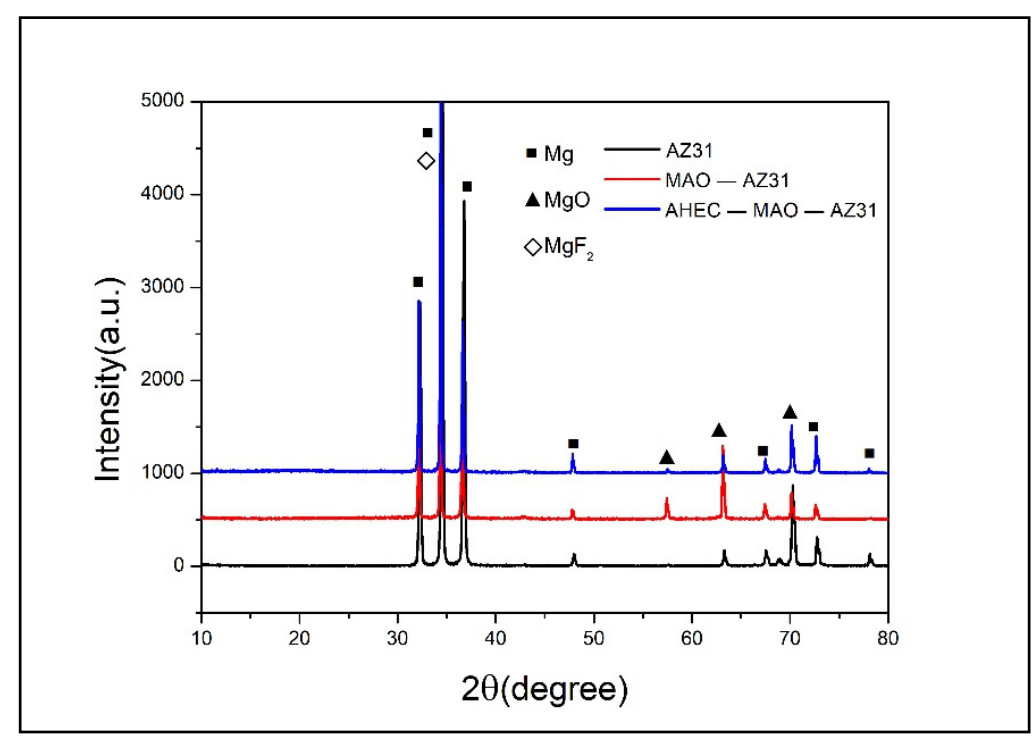

Figure 3. X-ray diffraction (XRD) pattern of AZ31, $\mathrm{MAO}+\mathrm{AZ31}$, and $\mathrm{AHEC}+\mathrm{MAO}+\mathrm{AZ31}$ specimens.

Figure 4 shows the FT-IR spectra of the AZ31 magnesium alloy substrate, $\mathrm{MAO}+\mathrm{AZ} 31$ magnesium alloy, AHEC + MAO + AZ31 magnesium alloy and pure AHEC. Based on the analysis of the pure hydroxyethyl cellulose samples, the spectral bands of the $-\mathrm{NH}_{2}$-functional groups appeared near the wavelength of $2847 \mathrm{~cm}^{-1}$, and the spectral bands of the $-\mathrm{CH}_{3},-\mathrm{CH}_{2}$, and $-\mathrm{CH}$ functional groups appeared at 1370, 1409 and $1456 \mathrm{~cm}^{-1}$, indicating that the AHEC was successfully prepared [43]. The spectrum of the $\mathrm{AHEC}+\mathrm{MAO}+\mathrm{AZ31}$ magnesium alloy was compared with that of pure AHEC, and the same characteristic peaks appeared at the same wavelengths. This proved that the AHEC was successfully prepared on the surface of the MAO + AZ31 magnesium alloy.

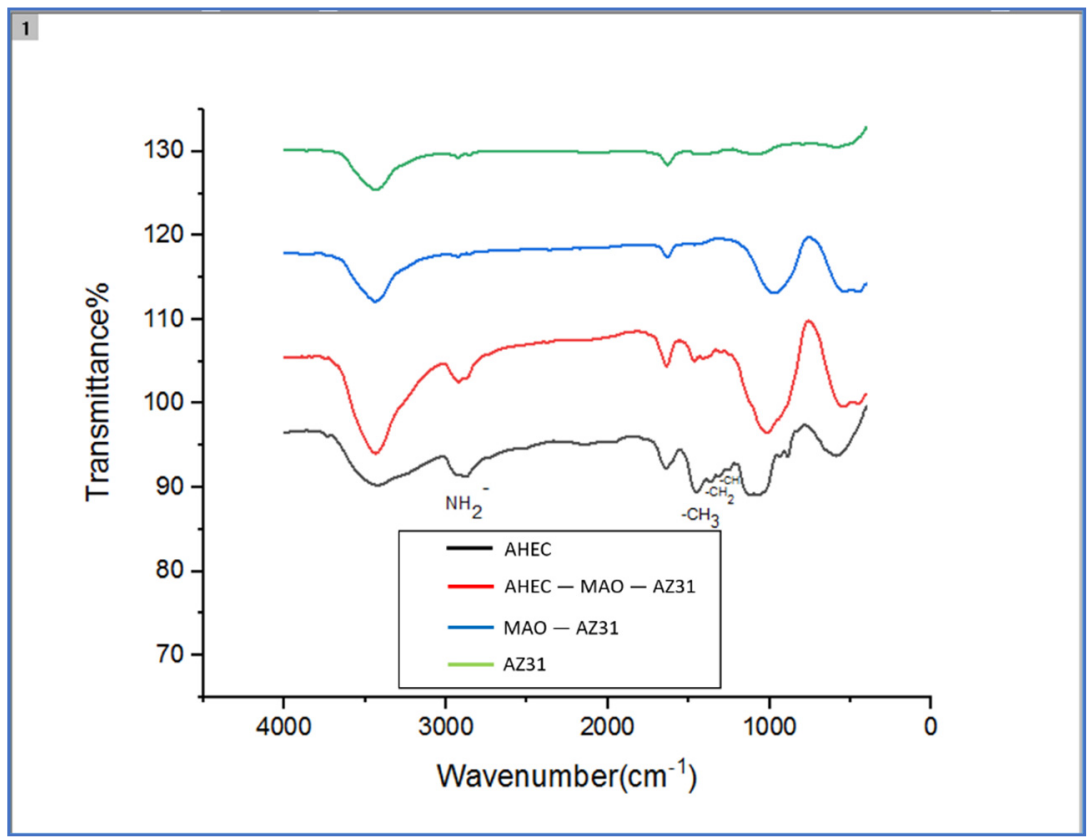

Figure 4. Fourier-transform infrared spectroscopy (FT-IR) spectrum of the AZ31, MAO + AZ31, $\mathrm{AHEC}+\mathrm{MAO}+\mathrm{AZ31}$, and pure AHEC .

Figure 5 and Table 2 show the elemental distribution of the MAO + AZ31 and AHEC + MAO + AZ31 magnesium alloys. Figure 5a shows the elemental contents of the MAO + AZ31 magnesium alloy. The micro-arc oxidized coating was composed of $\mathrm{Na}$, 
$\mathrm{O}, \mathrm{F}, \mathrm{P}, \mathrm{K}$ and small amounts of $\mathrm{C}$ and N. In Figure $5 \mathrm{~b}$, due to the presence of the AHEC, the contents of $\mathrm{C}$ and $\mathrm{N}$ in the samples increased to $47.95 \%$ and $4.88 \%$, respectively. This also proved that the AHEC was successfully prepared on the surface of the MAO + AZ31 magnesium alloy.
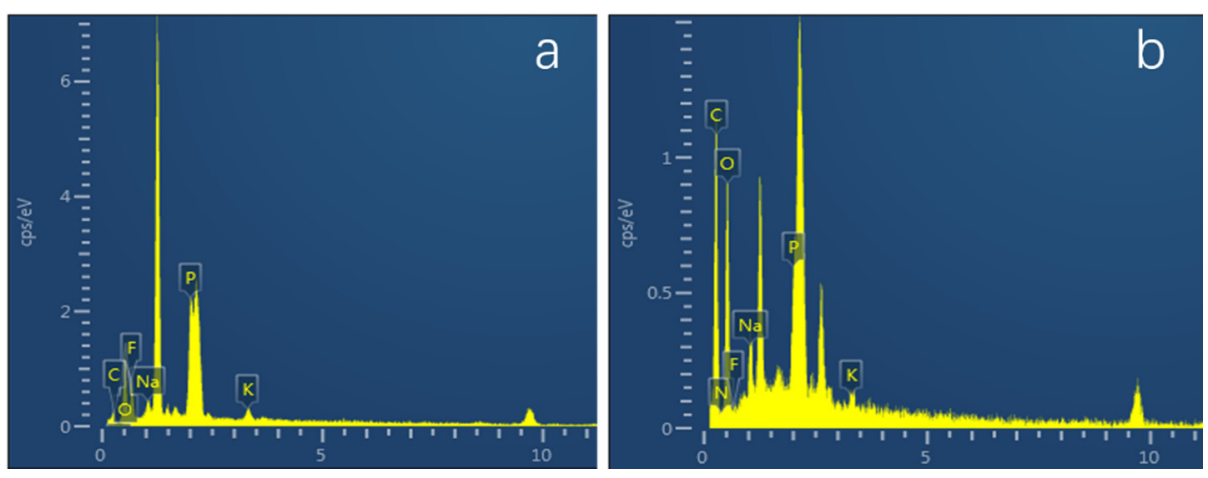

Figure 5. Energy-dispersive $X$-ray spectroscopy (EDS) determination of elemental distributions in (a) $\mathrm{MAO}+\mathrm{AZ31}$ and (b) AHEC + MAO + AZ31.

Table 2. EDS of samples (Round numbers).

\begin{tabular}{cccccccc}
\hline $\mathbf{W t} \%$ & $\mathbf{C}$ & $\mathbf{N}$ & $\mathbf{0}$ & $\mathbf{F}$ & $\mathbf{N a}$ & $\mathbf{P}$ & $\mathbf{K}$ \\
\hline $\mathrm{MAO}+\mathrm{AZ31}$ & 15 & 3 & 33 & 24 & 7 & 16 & 2 \\
$\mathrm{AHEC}+\mathrm{MAO}+\mathrm{AZ} 31$ & 48 & 5 & 38 & 1 & 4 & 3 & 1 \\
\hline
\end{tabular}

\subsection{Corrosion Resistance Analysis}

\subsubsection{Electrochemical Polarization Curve}

Figure 6 shows the potentiodynamic curves of the samples immersed in SBF at room temperature. Table 3 shows the corrosion current density at OCP and open circuit potential $(\mathrm{OCP})$ obtained by fitting the potentiodynamic curves.

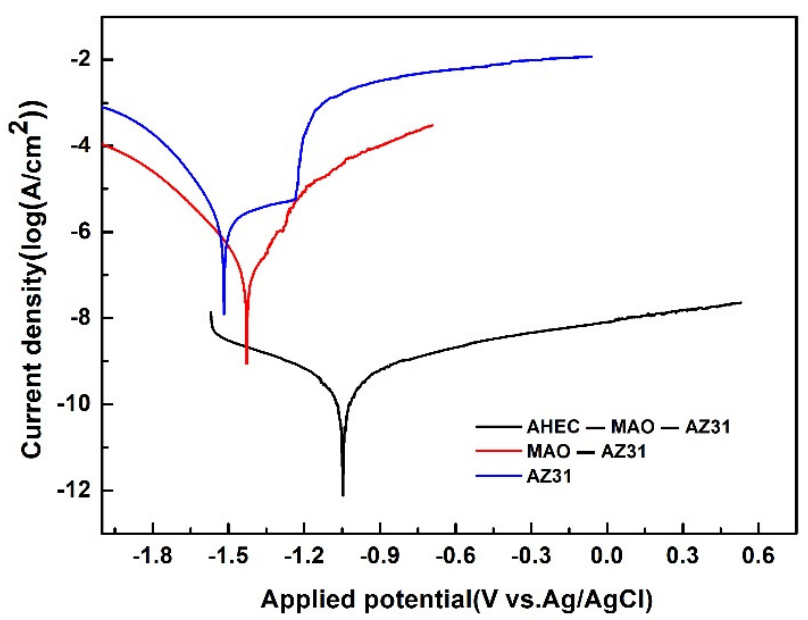

Figure 6. Potentiodynamic polarization curves for AZ31, MAO + AZ31, and AHEC + MAO + AZ31 in simulated body fluid (SBF) at room temperature. 
Table 3. Relative electrochemical parameters (mean \pm standard deviation).

\begin{tabular}{ccc}
\hline Samples & $\boldsymbol{E}_{\text {corr }}(\mathbf{V}$ vs. $\mathbf{A g} / \mathbf{A g C l})$ & $\boldsymbol{I}_{\text {corr }}\left(\mathbf{A} / \mathbf{c m}^{2}\right)$ \\
\hline AZ31 & $-1.526 \pm 0.002$ & $1.557 \pm 0.001 \times 10^{-6}$ \\
MAO + AZ31 & $-1.405 \pm 0.005^{*}$ & $1.121 \pm 0.003 \times 10^{-9} *$ \\
AHEC + MAO + AZ31 & $-1.072 \pm 0.004^{* \#}$ & $2.401 \pm 0.004 \times 10^{-10 * \#}$
\end{tabular}

* Compared with AZ31 magnesium alloy alone, the difference was statistically significant $(p<0.05) .{ }^{\#}$ Compared with MAO + AZ31 magnesium alloy, the difference of AHEC + MAO + AZ31 magnesium alloy was statistically significant $(p<0.05)$.

As shown in Table 3, the OCP of the AHEC + MAO + AZ31 magnesium alloy was more forward than that of the AZ31 magnesium alloy group $(-1.072 \pm 0.004 \mathrm{~V})$ and the MAO + AZ31 magnesium alloy group $(-1.405 \pm 0.005 \mathrm{~V})$. The corrosion current density $\left((2.401 \pm 0.004) \times 10^{-10} \mathrm{~A} / \mathrm{cm}^{2}\right)$ was lower than that of the AZ31 magnesium alloy group $\left((1.557 \pm 0.001) \times 10^{-6} \mathrm{~A} / \mathrm{cm}^{2}\right)$ and the $\mathrm{MAO}+\mathrm{AZ31}$ magnesium alloy group $\left((1.121 \pm 0.003) \times 10^{-9} \mathrm{~A} / \mathrm{cm}^{2}\right)$. Compared with the AZ31 magnesium alloy substrate, the OCP of the AHEC + MAO + AZ31 magnesium alloy group got more forward by $450 \mathrm{mV}$, and the corrosion current density at OCP decreased $10^{4}$ times [44]. The higher corrosion potential and lower corrosion current density at OCP of the coating corresponded to a lower corrosion rate and a higher corrosion resistance.

\subsubsection{Hydrogen Evolution Experiment}

Figure 7 shows the hydrogen gas volume change of the AZ31, MAO + AZ31 and AHEC $+\mathrm{MAO}+\mathrm{AZ} 31$ in SBF solution at a constant temperature $\left(37^{\circ} \mathrm{C}\right)$ over seven days. The average hydrogen gas forming rate of the AZ31 magnesium alloy was $3.41 \mathrm{~mL} / \mathrm{cm}^{2} / \mathrm{d}$, and those of the $\mathrm{MAO}+\mathrm{AZ} 31$ and AHEC + MAO + AZ31 groups were 0.31 and $0.15 \mathrm{~mL} / \mathrm{cm}^{2} / \mathrm{d}$, respectively. Compared with the other groups, the average hydrogen gas forming rate of the AHEC + MAO + AZ31 group was the lowest. This also indicated that the AHEC coating could effectively reduce the degradation rate of the AZ31 magnesium alloy in the SBF. Therefore, the AHEC coating could significantly improve the corrosion resistance of the AZ31 magnesium alloy [43].

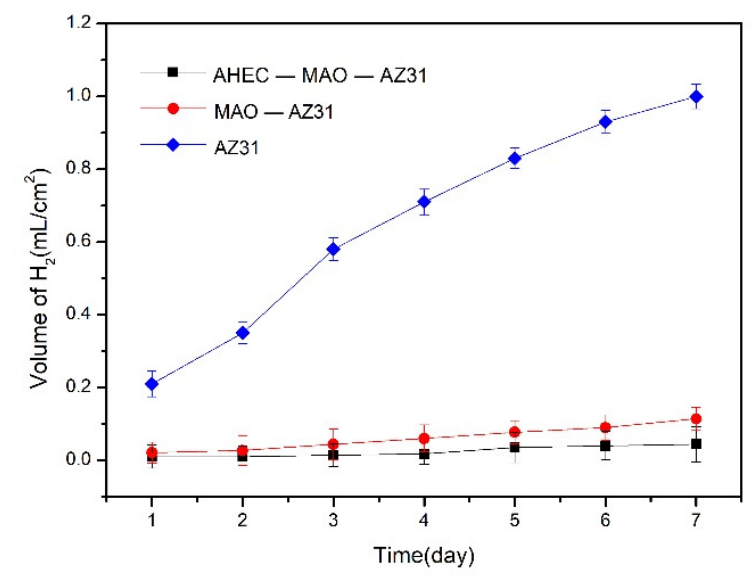

Figure 7. Volume of hydrogen released per unit area of AZ31, MAO + AZ31, and AHEC + MAO + AZ31 samples immersed at $37^{\circ} \mathrm{C}$ for 7 days.

\subsubsection{Long-Term Immersion Experiment}

Figure 8 is a photograph of the corroding surface of each group immersed in SBF at $37^{\circ} \mathrm{C}$ for $0-2784 \mathrm{~h}$. From top to bottom, they are AZ31 group, MAO + AZ31 group and $\mathrm{AHEC}+\mathrm{MAO}+\mathrm{AZ31}$ group. The surface of the AZ31 group began to corrode after $24 \mathrm{~h}$ of soaking, and the surface corrosion was obvious at $72 \mathrm{~h}$. During this time, there was no obvious change on the surface of the MAO coating group and the AHEC + MAO composite 
coating group. When immersed to $144 \mathrm{~h}$, the surface of the AZ31 group continued to corrode, while in the MAO group there were two corrosion spots. No obvious corrosion occurred on the surface of the AHEC + MAO group. When the immersion time was $696 \mathrm{~h}$, the corrosion area of AZ31 group continued to expand; the corrosion area of the MAO group increased; the surface of AHEC + MAO group was gray. When the immersion time was $2784 \mathrm{~h}, \mathrm{AZ} 31$ magnesium alloy had a large area of black corrosion; the surface was rough and accompanied by pits; extensive corrosion spots appeared on the surface of the MAO coating, and corrosion cracks occurred; there was a corrosion spot on the surface of the AHEC + MAO group. Through long-term immersion and different immersion time photos, it was found that the coating can effectively improve the corrosion resistance of magnesium alloys. Moreover, compared with a single MAO coating, the AHEC + MAO composite coating could more effectively improve the corrosion resistance of magnesium alloys.

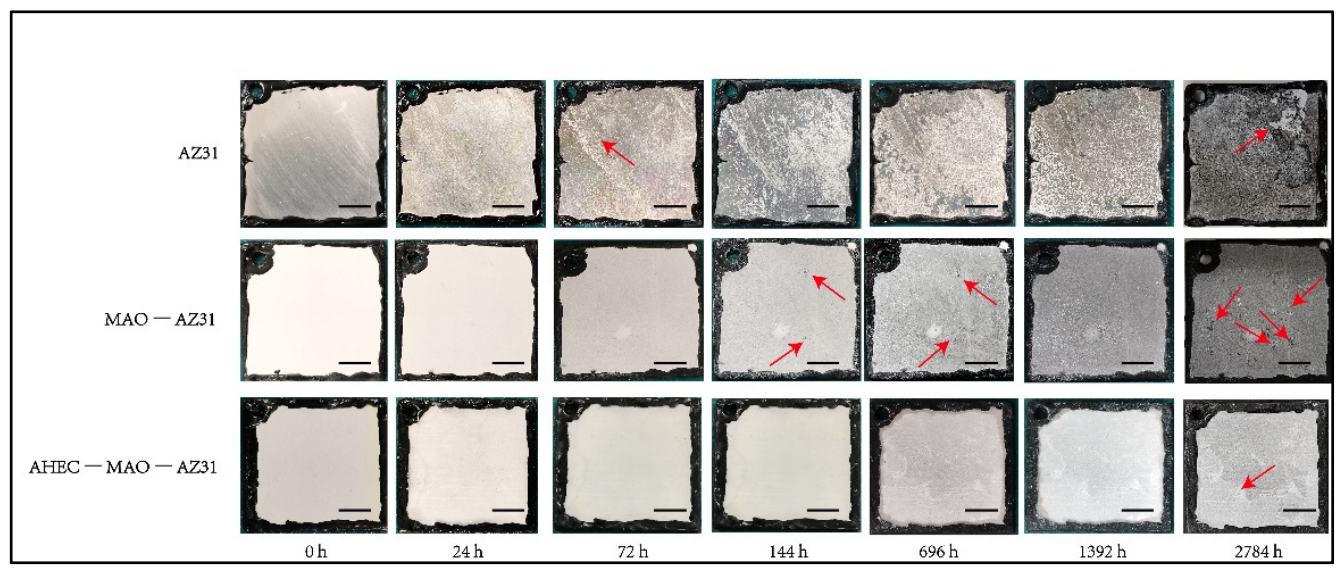

Figure 8. Long-term soaking diagram of each group. The red arrows indicate corrosion points. Scale bar $=5 \mathrm{~mm}$.

\subsection{Cytotoxicity Test}

\subsubsection{CCK-8 Test}

The toxicity of each group to MC3T3-E1 cells was determined by an indirect assay. Figure 9 shows the changes in the cell activity over time. The pure AZ31 magnesium alloy had good biocompatibility, and the cell proliferation rate was comparable to the negative group. The biocompatibility of the MAO group was poor, and the cell proliferation rates on days 1,3 and 5 were less than $80 \%$. This is consistent with the findings of Fu et al. [45]. The cell proliferation rate of the AHEC group was significantly higher than that of the MAO group, indicating that the biocompatibilities of the samples increased with the addition of AHEC.

\subsubsection{Observation of Cell Morphology}

The morphologies of the MC3T3-E1 cells cultured in the extract solution of each group on day 5 were photographed using inverted microscopy $(20 \times)$. Figure 10 shows the cell morphology and density of each group. The negative group and AZ31 magnesium alloy group had the most cells, followed by the AHEC group, and the MAO group had fewest number of cells. This indicated that the AHEC coating could improve the cellular compatibility of the MAO + AZ31 magnesium alloy, which is also consistent with the results of the CCK-8 test. 


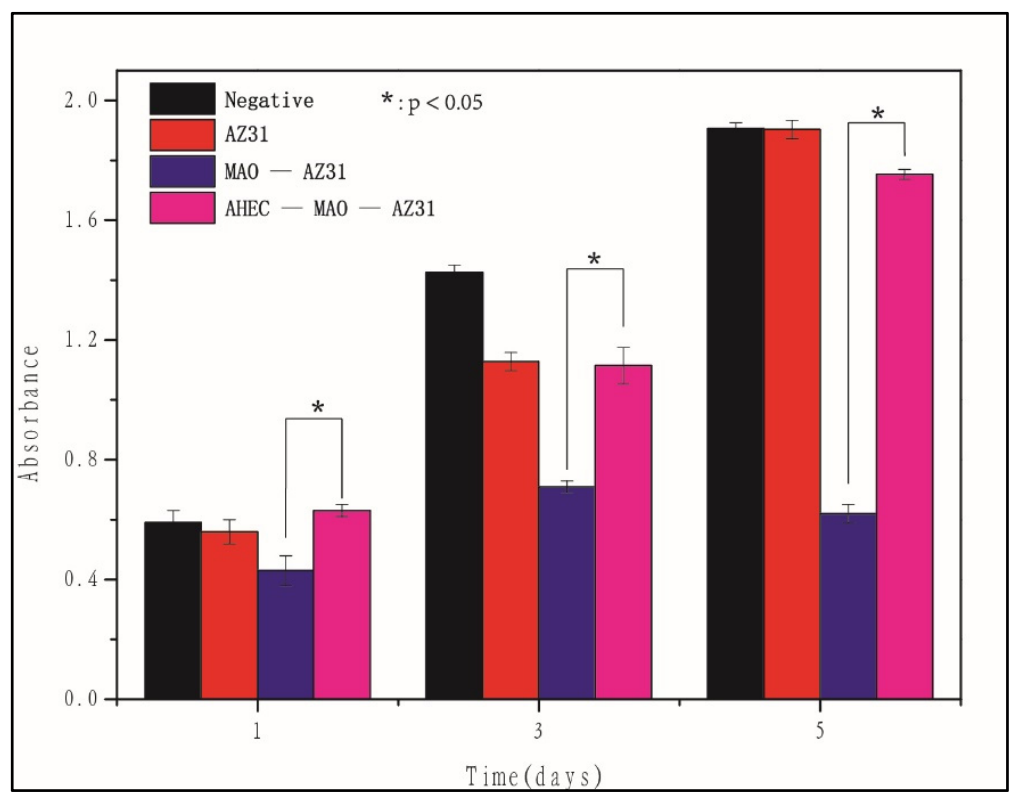

Figure 9. The cell viability of AZ31, MAO + AZ31 and AHEC + MAO + AZ31 specimens.

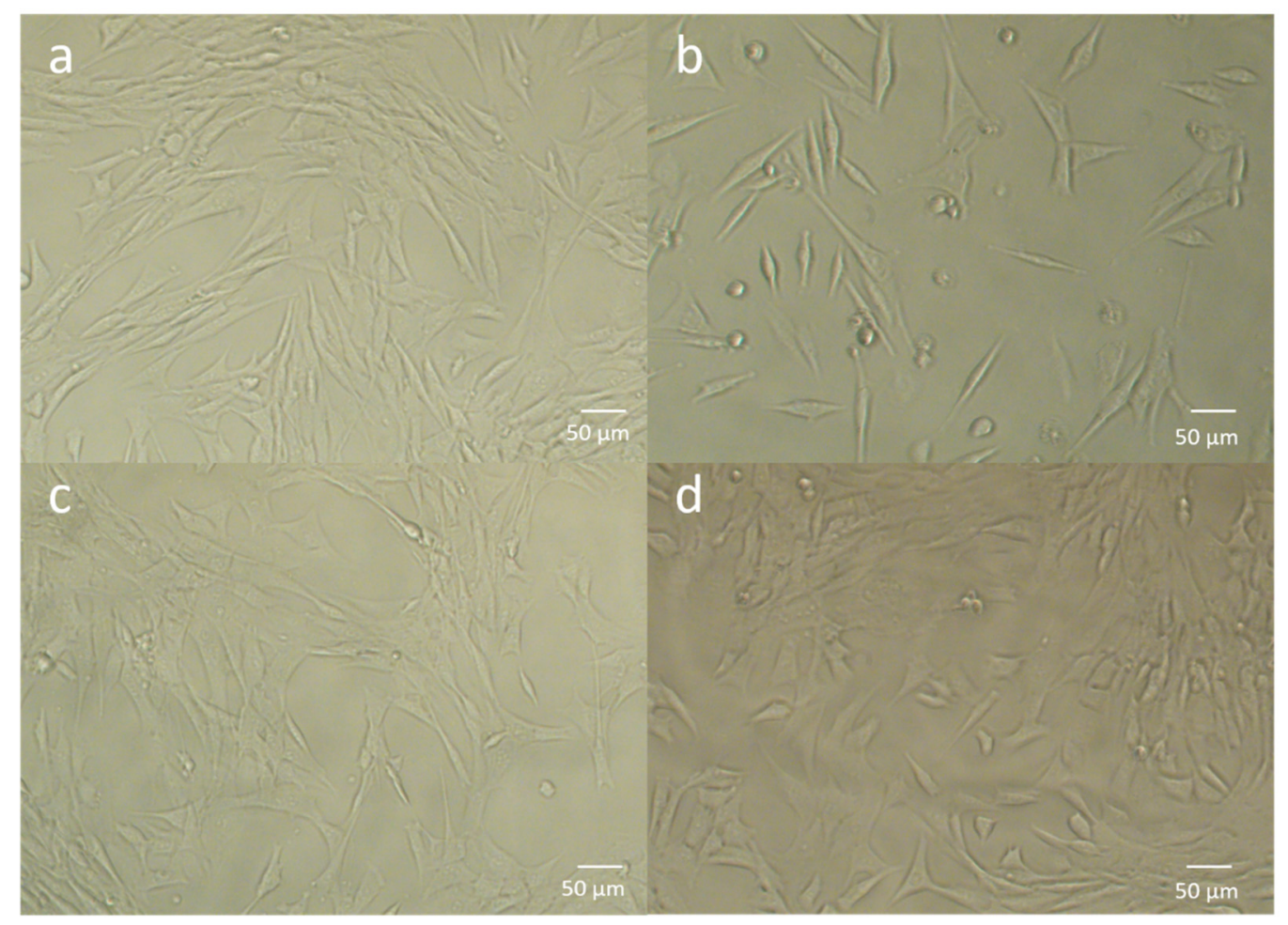

Figure 10. Inverted microscopy images $(20 \times)$ of the MC3T3-E1 cells cultured with extracts from the (a) AZ31, (b) MAO + AZ31, (c) AHEC + MAO + AZ31 specimens, and (d) negative control group after $5 \mathrm{~d}$.

\section{Conclusions}

1. Compared to the pure AZ31 magnesium alloy, the corrosion resistances of the MAO + AZ31 magnesium alloy and the AHEC + MAO + AZ31 magnesium alloy were significantly improved. The hydrogen evolution experiment and long-term immersion experiment showed that the corrosion resistance of the AHEC + MAO + AZ31 magnesium alloy was better than that of the $\mathrm{MAO}+\mathrm{AZ} 31$ magnesium alloy. 
2. CCK-8 and cell morphology observations showed that the extract of the AZ31 magnesium alloy had no toxic effect on the growth of MC3T3-E1 cells. The biocompatibility of the MAO + AZ31 magnesium alloy could be improved by the AHEC coating.

3. In summary, the application of the AHEC to seal the MAO coating could significantly improve the corrosion resistance and biocompatibility of the MAO AZ31 magnesium alloy, and thus, this material has potential application value as a medical implant material.

Author Contributions: Conceptualization, L.Z., J.L. and B.C.; methodology, L.Z. and Y.W. (Yuanzhi Wu); software, Y.W. (Yuanzhi Wu) and Y.W. (Yu Wei); validation, T.Z.; data curation, G.Z.; writingoriginal draft preparation, L.Z.; writing - review and editing, L.Z. and B.C.; funding acquisition, B.C. All authors have read and agreed to the published version of the manuscript.

Funding: This research was funded by Key Research and Development Program of Gansu Province, grant number 20YF8FA071.

Acknowledgments: This project is supported by the Key Research and Development Program of Gansu Province. We sincerely appreciate the technical and material support from Lanzhou Institute of Chemical Physics, Chinese Academy of Sciences.

Conflicts of Interest: The authors declare no conflict of interest.

\section{References}

1. Jung, H.D.; Jang, T.S.; Wang, L.; Kim, H.E.; Koh, Y.H.; Song, J. Novel strategy for mechanically tunable and bioactive metal implants. Biomaterials 2015, 37, 49-61. [CrossRef]

2. Gawkrodger, D.J. Metal sensitivities and orthopaedic implants revisited: The potential for metal allergy with the new metal-onmetal joint prostheses. Br. J. Dermatol. 2015, 148, 1089-1093. [CrossRef] [PubMed]

3. Schell, H.; Zimpfer, E.; Schmidt-Bleek, K.; Jung, T.; Duda, G.N.; Ryd, L. Treatment of osteochondral defects: Chondrointegration of metal implants improves after hydroxyapatite coating. Knee Surg. Sports Traumatol. Arthrosc. 2019, 27, 3575-3582. [CrossRef]

4. Li, Y.; Zhou, J.; Pavanram, P.; Leeflang, M.; Fockaert, L.; Pouran, B.; Tümer, N.; Schröder, K.-U.; Mol, J.; Weinans, H.; et al. Additively manufactured biodegradable porous magnesium. Acta Biomater. 2018, 67, 378-392. [CrossRef]

5. Wong, H.M.; Yeung, K.W.K.; Lam, K.O.; Tam, V.; Chu, P.K.; Luk, K.D.K.; Cheung, K.M.C. A biodegradable polymer-based coating to control the performance of magnesium alloy orthopaedic implants. Biomaterials 2010, 31, 2084-2096. [CrossRef]

6. Kraus, T.; Fischerauer, S.; Treichler, S.; Martinelli, E.; Weinberg, A.M. The influence of biodegradable magnesium implants on the growth plate. Acta Biomater. 2018, 66, 109-117. [CrossRef]

7. Chen, L.; Zheng, R.; Yongdong, X.; Song, P.; Xinbing, Z.; Ying, Z. Biodegradable Magnesium Alloys Developed as Bone Repair Materials: A Review. Scanning 2018, 2018, 1-15.

8. Zhao, D.; Witte, F.; Lu, F.; Wang, J.; Qin, L. Current status on clinical applications of magnesium-based orthopaedic implants: A review from clinical translational perspective. Biomaterials 2017, 112, 287-302. [CrossRef]

9. He, R.; Liu, R.; Chen, Q.; Zhang, H.; Wang, J.; Guo, S. In vitro degradation behavior and cytocompatibility of Mg-6Zn-Mn alloy. Mater. Lett. 2018, 228, 77-80. [CrossRef]

10. Hornberger, H.; Virtanen, S.; Boccaccini, A.R. Biomedical coatings on magnesium alloys-A review. Acta Biomater. 2012, 8, 2442-2455. [CrossRef] [PubMed]

11. Song, G.L.; Song, S. A Possible Biodegradable Magnesium Implant Material. Adv. Eng. Mater. 2010, 9, 298-302. [CrossRef]

12. Xin, Y.; Hu, T.; Chu, P.K. In vitro studies of biomedical magnesium alloys in a simulated physiological environment: A review. Acta Biomater. 2011, 7, 1452-1459. [CrossRef] [PubMed]

13. Singh, S.; Kumar, R.M.; Kuntal, K.K.; Gupta, P.; Das, S.; Jayaganthan, R.; Roy, P.; Lahiri, D. Sol-Gel Derived Hydroxyapatite Coating on Mg-3Zn Alloy for Orthopedic Application. JOM 2015, 67, 702-712. [CrossRef]

14. Zartner, P.; Cesnjevar, R.; Singer, H.; Weyand, M. First successful implantation of a biodegradable metal stent into the left pulmonary artery of a preterm baby. Catheter. Cardiovasc. Interv. 2010, 66, 590-594. [CrossRef] [PubMed]

15. Seal, C.K.; Vince, K.; Hodgson, M.A. Biodegradable surgical implants based on magnesium alloys-A review of current research. Iop Conf. 2009, 4, 012011. [CrossRef]

16. Kamrani, S.; Fleck, C. Biodegradable magnesium alloys as temporary orthopaedic implants-A Review. BioMetals 2019, 32, 185-193. [CrossRef] [PubMed]

17. Fischerauer, S.F.; Kraus, T.; Wu, X.; Tangl, S.; Sorantin, E.; Hänzi, A.C.; Löffler, J.F.; Uggowitzer, P.J.; Weinberg, A.M. In vivo degradation performance of micro-arc-oxidized magnesium implants: A micro-CT study in rats. Acta Biomater. 2013, 9, 5411-5420. [CrossRef]

18. Wan, P.; Tan, L.; Yang, K.; Metal, I.O.; Sciences, C.A.O. Surface Modification on Biodegradable Magnesium Alloys as Orthopedic Implant Materials to Improve the Bio-adaptability:A Review. J. Mater. Sci. Technol. 2016, 32, 827-834. [CrossRef] 
19. Editor's Comment on: The history of biodegradable magnesium implants: A review. Acta Biomater. 2015, 23, S27. [CrossRef]

20. Waizy, H.; Diekmann, J.; Weizbauer, A.; Reifenrath, J.; Bartsch, I.; Neubert, V.; Schavan, R.; Windhagen, H. In vivo study of a biodegradable orthopedic screw (MgYREZr-alloy) in a rabbit model for up to 12 months. J. Biomater. Appl. 2013, 28, 667-675. [CrossRef]

21. Sankara Narayanan, T.S.N.; Park, I.S.; Lee, M.H. Strategies to improve the corrosion resistance of microarc oxidation (MAO) coated magnesium alloys for degradable implants: Prospects and challenges. Prog. Mater. Sci. 2014, 60, 1-71. [CrossRef]

22. Blawert, C.; Dietzel, W.; Ghali, E.; Song, G. Anodizing Treatments for Magnesium Alloys and Their Effect on Corrosion Resistance in Various Environments. Adv. Eng. Mater. 2006, 8, 511-533. [CrossRef]

23. Cui, L.-Y.; Gao, S.-D.; Li, P.-P.; Zeng, R.-C.; Zhang, F.; Li, S.-Q.; Han, E.-H. Corrosion resistance of a self-healing micro-arc oxidation/polymethyltrimethoxysilane composite coating on magnesium alloy AZ31. Corros. Sci. 2017, 118, 84-95. [CrossRef]

24. Dong, K.; Song, Y.; Shan, D.; Han, E.-H. Corrosion behavior of a self-sealing pore micro-arc oxidation film on AM60 magnesium alloy. Corros. Sci. 2015, 100, 275-283. [CrossRef]

25. Satyanarayana, S.; Busch, E. A novel technique for sealing porous dielectrics. Solid State Technol. 2005, 48, 24-26.

26. Shi, P.; Ng, W.F.; Wong, M.H.; Cheng, F.T. Improvement of corrosion resistance of pure magnesium in Hanks' solution by microarc oxidation with sol-gel $\mathrm{TiO}_{2}$ sealing. J. Alloy. Compd. 2009, 469, 286-292. [CrossRef]

27. Dou, J.; Yu, H.; Chen, C. Preparation and characterization of composite coating on Mg-1.74Zn-0.55Ca alloy by micro-arc oxidation combined with sol-gel method. Mater. Lett. 2019, 255, 126578. [CrossRef]

28. Xia, W.; Li, N.; Deng, B.; Zheng, R.; Chen, Y. Corrosion behavior of a sol-gel ZrO2 pore-sealing film prepared on a micro-arc oxidized aluminum alloy. Ceram. Int. 2019, 45, 11062-11067. [CrossRef]

29. Hidayat, B.J.; Felby, C.; Johansen, K.S.; Thygesen, L.G. Cellulose is not just cellulose: A review of dislocations as reactive sites in the enzymatic hydrolysis of cellulose microfibrils. Cellulose 2012, 19, 1481-1493. [CrossRef]

30. Kamel, S.; Ali, N.; Jahangir, K.; Shah, S.M.; El-Gendy, A.A. Pharmaceutical significance of cellulose: A review. Express Polym. Lett. 2008, 2, 758-778. [CrossRef]

31. Missoum, K.; Belgacem, M.N.; Bras, J. Nanofibrillated Cellulose Surface Modification: A Review. Materials 2013, 6, 1745-1766. [CrossRef]

32. Lu, Z.; Huang, J.; Songfeng, E.; Li, J.; Zhang, M. All cellulose composites prepared by hydroxyethyl cellulose and cellulose nanocrystals through the crosslink of polyisocyanate. Carbohydr. Polym. 2020, 250, 116919. [CrossRef] [PubMed]

33. Klemm, D.; Heublein, B.; Fink, H.P.; Bohn, A. Cellulose: Fascinating Biopolymer and Sustainable Raw Material (p3358-3393). Angew. Chem. Int. Ed. 2010, 44, 3358-3393. [CrossRef] [PubMed]

34. Liesiene, J.; Kazlauske, J. Functionalization of cellulose: Synthesis of water-soluble cationic cellulose derivatives. Cellul. Chem. Technol. 2013, 47, 515-525.

35. Kokubo, T.; Takadama, H. How useful is SBF in predicting in vivo bone bioactivity? Biomaterials 2006, 27, 2907-2915. [CrossRef]

36. Bakhsheshi-Rad, H.R.; Hamzah, E.; Kasiri-Asgarani, M.; Jabbarzare, S.; Iqbal, N.; Kadir, M.R.A. Deposition of nanostructured fluorine-doped hydroxyapatite-polycaprolactone duplex coating to enhance the mechanical properties and corrosion resistance of Mg alloy for biomedical applications. Mater. Eng. C Mater. Biol. Appl. 2016, 60, 526-537. [CrossRef] [PubMed]

37. Han, X.G.; Zhu, F.; Zhu, X.P.; Lei, M.K.; Xu, J.J. Electrochemical corrosion behavior of modified MAO film on magnesium alloy AZ31 irradiated by high-intensity pulsed ion beam. Surface Coat. Technol. 2013, 228, S164-S170. [CrossRef]

38. Liu, S.; Qi, Y.; Peng, Z.; Liang, J. A chemical-free sealing method for Micro-arc oxidation coatings on AZ31 Mg alloy. Surf. Coat. Technol. 2020, 406, 126655. [CrossRef]

39. Shang, W.; Chen, B.; Shi, X.; Chen, Y.; Xiao, X. Electrochemical corrosion behavior of composite MAO/sol-gel coatings on magnesium alloy AZ91D using combined micro-arc oxidation and sol-gel technique. J. Alloys Compd. 2009, 474, 541-545. [CrossRef]

40. Li, N.; Chen, Y.; Deng, B.; Yue, J.; Qu, W.; Yang, H.; He, Y.; Xia, W.; Li, L. Low temperature UV assisted sol-gel preparation of $\mathrm{ZrO} 2$ pore-sealing films on micro-arc oxidized magnesium alloy AZ91D and their electrochemical corrosion behaviors. J. Alloys Compd. 2019, 792, 1036-1044. [CrossRef]

41. Tang, M.; Liu, H.; Li, W.; Zhu, L. Effect of zirconia sol in electrolyte on the characteristics of microarc oxidation coating on AZ91D magnesium. Mater. Lett. 2011, 65, 413-415. [CrossRef]

42. Wang, S.; Fu, L.; Nai, Z.; Liang, J.; Cao, B. Comparison of Corrosion Resistance and Cytocompatibility of $\mathrm{MgO}$ and $\mathrm{ZrO} 2 \mathrm{Coatings}$ on AZ31 Magnesium Alloy Formed via Plasma Electrolytic Oxidation. Coatings 2018, 8, 441. [CrossRef]

43. Zhu, B.; Xu, Y.; Sun, J.; Yang, L.; Guo, C.; Liang, J.; Cao, B. Preparation and Characterization of Aminated Hydroxyethyl Cellulose-Induced Biomimetic Hydroxyapatite Coatings on the AZ31 Magnesium Alloy. Metals 2017, 7, 214. [CrossRef]

44. Guo, H.; An, M. Growth of ceramic coatings on AZ91D magnesium alloys by micro-arc oxidation in aluminate-fluoride solutions and evaluation of corrosion resistance. Appl. Surf. Sci. 2005, 246, 229-238. [CrossRef]

45. Fu, L.; Yang, Y.; Zhang, L.; Wu, Y.; Cao, B. Preparation and Characterization of Fluoride-Incorporated Plasma Electrolytic Oxidation Coatings on the AZ31 Magnesium Alloy. Coatings 2019, 9, 826. [CrossRef] 